\title{
A novel PPARa agonist propane-2-sulfonic acid octadec-9-enyl-amide inhibits inflammation in THP-1 cells
}

Yun Zhao a, ${ }^{\text {, }}$ Lu Yan ${ }^{\text {a, } 1}$, Xiu-Mei Luo ${ }^{\text {a, } 1}$, Lu Peng ${ }^{\text {a }}$, Han Guo ${ }^{\text {a }}$ Zuo Jing ${ }^{\text {a }}$, Li-Chao Yang $^{\mathrm{a}}$, Rong Hu ${ }^{\mathrm{a}}$, XuanWang ${ }^{\mathrm{a}}$, Xue-Feng Huang ${ }^{\mathrm{b}}$, Yi-Qing Wang ${ }^{\mathrm{b}, ~ *}$, and Xin Jin ${ }^{\mathrm{a}}$ *

${ }^{a}$ Xiamen Key Laboratory of Chiral Drugs, Medical College, Xiamen University, Xiamen 361000, China

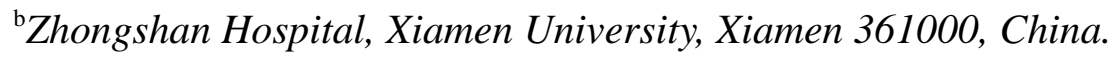

*Corresponding authors. Tel./fax: +86 5922188676.

E-mail address: wang_gina@163.com (Yi-Qing Wang) and xinjin@xmu.edu.cn (Xin Jin)

${ }^{1}$ These authors contributed equally to this work and should be considered co-first authors.

\section{ABSTRACT}

Our group synthesized propane-2-sulfonic acid octadec-9-enyl-amide (N15), a novel peroxisome proliferator activated receptor alpha (PPAR $\alpha)$ agonist. Because PPAR $\alpha$ activation is associated with inflammation control, we hypothesize that N15 may have anti-inflammatory effects. We investigated the effect of N15 on the regulation of inflammation in THP-1 cells stimulated with lipopolysaccharide (LPS). In particular, 
we assessed the production of chemokines, adhesion molecules and proinflammatory cytokines, three important types of cytokines that are released from monocytes and are involved in the development of atherosclerosis. The results showed that N15 remarkably reduced the mRNA expression of chemokines, such as monocyte chemotactic protein 1 (MCP-1, or CCL2), interleukin-8 (IL-8) and interferon-inducible protein-10 (IP-10, or CXCL10), and proinflammatory cytokines, such as tumor necrosis factor- $\alpha$ (TNF- $\alpha$ ), interleukin-1 $\beta$ (IL-1 $\beta)$ and interleukin-6 (IL-6). N15 also decreased the protein expression of vascular cell adhesion molecule (VCAM) and matrix metalloproteinase (MMP) 2 and 9. The reduction in the expression of cytokine mRNAs observed following N15 treatment was abrogated in THP-1 cells treated with PPAR $\alpha$ siRNA, indicating that the anti-inflammatory effects of N15 are dependent on PPAR $\alpha$ activation. Toll-like receptor 4 (TLR4) / nuclear factor- $\kappa \mathrm{B}(\mathrm{NF}-\kappa \mathrm{B})$ and signal transducer and activator of transcription 3 (STAT3) inhibition, which are dependent on PPAR $\alpha$ activation, were also involved in the mechanism underlying the anti-inflammatory effects of N15. In conclusion, the novel PPAR $\alpha$ agonist, N15, exerts notable anti-inflammatory effects, which are mediated via PPAR $\alpha$ activation and TLR4/NF- $\kappa$ B and STAT3 inhibition, in LPS-stimulated THP-1 cells. In our study, N15 exhibits promise for the treatment of atherosclerosis.

Keywords:

Propane-2-sulfonic acid octadec-9-enyl-amide

Peroxisome proliferator activated receptor alpha 
Proinflammatory cytokines

Adhesion molecules

Atherosclerosis

\section{Introduction}

Cardiovascular diseases have represented the main cause of morbidity and mortality in Western societies since the 20th century and are primarily a consequence of atherosclerosis. Atherosclerosis is classified as a chronic inflammatory disease, as the immune response plays a significant role in all phases of the atherosclerotic process (Fernandez, 2008). Immune cells, such as monocytes, macrophages, and T-cells, are crucial in the development of atheroma, as they release pro-inflammatory cytokines, adhesion molecules and chemokines. Therefore, the modulation of the release of these cytokines from these cells may be a useful therapeutic strategy for the treatment of atherosclerosis.

PPAR $\alpha$ is of particular importance in alleviating atherosclerosis due to its roles in regulating lipid metabolism and inflammation (Chawla, 2010; Chen et al., 2013; Khera et al., 2015; Varga et al., 2011). Synthetic PPAR $\alpha$ agonists, including fibrates, which are used clinically, improve dyslipideamia and prevent the development of atherosclerosis (Pang et al., 2012). However, fibrates (e.g. fenofibrate) are weak PPAR $\alpha$ agonists with low potency, and can cause some side effects, such as liver damage (Schafer et al., 2012). The endogenous PPAR $\alpha$ agonist, oleoylethanolamide (OEA), may be an effective anti-atherosclerotic agent, and it acts by inhibiting 
oxidation, inflammation and hyperlipidemia (Chen et al., 2011; Fu et al., 2007). Unfortunately, OEA is vulnerable to enzymatic hydrolysis to oleic acid and ethanolamine and thus is not expected to be orally active (Fu et al., 2008).

Propane-2-sulfonic acid octadec-9-enyl-amide (N15), a novel PPAR $\alpha$ agonist that was synthesized in our laboratory, is an analog of OEA. N15 is resistant to enzymatic hydrolysis and retains its potent ability to activate PPAR $\alpha$ (Chen et al., 2015). Because OEA and fibrates have anti-inflammatory effects, we hypothesize that N15 will also be able to alleviate inflammation. In order to prove this hypothesis, in this study, we testified the inhibitory effect of N15 on the release of pro-inflammatory cytokines, chemokines and adhesion molecules in monocytes.

\section{Materials and Methods}

\subsection{Reagents}

Fetal bovine serum (FBS), penicillin and streptomycin were purchased from Gibco BRL (Carlsbad, CA, USA). LPS and fenofibrate were purchased from Sigma (St. Louis, MO, USA). N15 (purity $\geqslant 98 \%$ ) was synthesized in our laboratory (Chen et al., 2015). The siRNA specific for PPAR $\alpha$ and negative control siRNA (NC siRNA) were purchased from Invitrogen Life Technologies (Carlsbad, CA, USA).

\subsection{Cell culture}

The human monocyte cell line, THP-1 (Cell Resource Center of the Shanghai Institutes for Biological Sciences, Chinese Academy of Sciences, Shanghai, China), were cultured in RPIM-1640 (Hyclone, Logan, UT, USA) supplemented with 10\% 
FBS, $100 \mathrm{U} / \mathrm{ml}$ penicillin, and $100 \mu \mathrm{g} / \mathrm{ml}$ streptomycin at $37^{\circ} \mathrm{C}$ with $5 \% \mathrm{CO}_{2}$. The cells were subcultured in suspension every 2 days until passage.

\subsection{Cell viability assay}

The MTS assay was used to evaluate the toxicity of N15 and fenofibrate on THP-1 cells. Briefly, THP- 1 cells were plated at $2 \times 10^{3}$ cells per well in 96 -well plates and stimulated with various concentrations of N15 or fenofibrate for $24 \mathrm{~h}$. Cell viability was measured with a CellTiter $96{ }^{\circledR}$ AQueous One Solution Cell Proliferation Assay kit (Promega, Fitchburg, WI, USA) according to the manufacturer's instructions. Absorbance was read at $490 \mathrm{~nm}$ on a Microplate Reader (Molecular Devices, Silicon Valley, CA, USA).Viability was calculated according to the following formula: Viability $(\%)=$ A490 (sample)/A490 (control) $\times 100 \%$.

\subsection{Quantitative real-time polymerase chain reaction ( $q P C R)$}

THP-1 cells were pretreated with varying concentrations of $\mathrm{N} 15(20,50,100 \mu \mathrm{M})$ and fenofibrate $(100 \mu \mathrm{M})$ or an equivalent volume of DMSO for $1 \mathrm{~h}$ before exposure to LPS $(1.0 \mu \mathrm{g} / \mathrm{ml})$ for another $12 \mathrm{~h}$. Total cellular RNA was extracted using TRIzol ${ }^{\circledR}$ (Invitrogen, Carlsbad, CA, USA), according to the manufacturer's instructions. cDNA was synthesized using a Reverse Transcription kit (Thermo Fisher, Boston, MA, USA). The primers were designed by Sangon Biotechnology (Shanghai, China), and their sequences are listed in Table 1. qPCR was performed with the 7300 Real Time PCR System (Applied Biosystems, Life Technologies Corporation, CA, USA), with the following cycling program: thermal activation for $30 \mathrm{~s}$ at $95^{\circ} \mathrm{C}$ and 40 cycles of PCR with melting for $5 \mathrm{~s}$ at $95^{\circ} \mathrm{C}$, followed by annealing/extension for $31 \mathrm{~s}$ at $60^{\circ} \mathrm{C}$. 
The expression of TNF- $\alpha$, IL-1 $\beta$, IL-6, IL-8, IP-10, MCP-1, PPAR $\alpha$, fatty-acid translocase (FAT/CD36) and uncoupling protein-2 (UCP-2) in individual samples were normalized to the expression of the control gene, glyceraldehyde-3-phosphate dehydrogenase (GAPDH).

\section{Table 1}

Primer sequences used for qPCR.

\begin{tabular}{|c|c|c|}
\hline \multirow[t]{2}{*}{ TNF- $\alpha$} & Forward & 5' TGCTTGTTCCTCAGCCTCTT 3' \\
\hline & Reverse & 5' CAGAGGGCTGATTAGAGAGAGGT 3' \\
\hline \multirow[t]{2}{*}{ IL-6 } & Forward & 5' CTTCGGTCCAGTTGCCTTCT 3' \\
\hline & Reverse & 5' GTGAGTGGCTGTCTGTGTGG 3' \\
\hline \multirow[t]{2}{*}{ IL-1 $\beta$} & Forward & 5' TCGCCAGTGAAATGATGGCTTA 3' \\
\hline & Reverse & 5' GTCCATGGCCACAACAACTGA 3' \\
\hline \multirow[t]{2}{*}{ IL-8 } & Forward & 5' TTTCAGAGACAGCAGAGCACA 3' \\
\hline & Reverse & 5' GCCAGCTTGGAAGTCATGTT 3' \\
\hline \multirow[t]{2}{*}{ IP-10 } & Forward & 5' GAAAGCAGTTAGCAAGGAAAGG 3' \\
\hline & Reverse & 5' TAGGGAAGTGATGGGAGAGG 3' \\
\hline \multirow[t]{2}{*}{ MCP-1 } & Forward & 5' AGGAACCGAGAGGCTGAGA 3' \\
\hline & Reverse & 5' CTATGAGCAGCAGGCACAGA 3' \\
\hline \multirow[t]{2}{*}{ PPAR $\alpha$} & Forward & 5' AATCCATCGGCGAGGATAG 3' \\
\hline & Reverse & 5' CCAGCTTGAGTCGAATCGTT 3' \\
\hline \multirow[t]{2}{*}{ UCP-2 } & Forward & 5' CTGGAGGTGGTCGGAGATAC3' \\
\hline & Reverse & 5' ATGAGGTTGGCTTTCAGGAG3' \\
\hline
\end{tabular}




\begin{tabular}{lll}
\hline CD36 & Forward & 5' AATGTAACCCAGGACGCTGA3' \\
& Reverse & 5' GCCACAGCCAGATTGAGAAC3' \\
GAPDH & Forward & 5' GCACCGTCAAGGCTGAGAAC 3' \\
& Reverse & 5' TGGTGAAGACGCCAGTGGA 3' \\
\hline
\end{tabular}

\subsection{Western blot analyses}

THP-1 cells were pretreated with varying concentrations of N15 or fenofibrate for $1 \mathrm{~h}$ before exposure to LPS for another $24 \mathrm{~h}$. Cellular protein was extracted using RIPA lysis and extraction buffer (Aidlab Biotechnologies, Beijing, China), according to the manufacturer's protocols. Protein concentration was measured using a Bicinchoninic Acid kit (Thermo Scientific). Then, $40 \mu \mathrm{g}$ of protein lysate was separated by $10 \%$ sodium dodecyl sulfate (SDS) electrophoresis, transferred onto polyvinylidene difluoride (PVDF) membranes (Millipore, Bedford, MA, USA), and immunoblotted with antibodies against PPAR $\alpha$ (1:1000 dilution; Abcam, Cambridge, UK), TLR4 (1:500, Cell Signaling Technology, Boston, USA), MMP2 (1:500; Abcam), MMP9 (1:500; Abcam), p65 (1:1000, Cell Signaling Technology), phospho-p65 (Ser536) (1:1000; Cell Signaling Technology), STAT3 (1:1000; Abcam), phospho-STAT3 (Tyr705) (1:1000, Cell Signaling Technology) and GAPDH (1:2000; Abcam). Subsequently, the membranes were incubated with horseradish peroxidase (HRP)-conjugated secondary antibodies (MultiSciences (Lianke) Biotech, Hangzhou, China) and visualized using an ECL Plus kit (Merck Millipore, Darmstadt, Germany). The relative density of the protein bands was quantified using an LAS 4000 Fujifilm 
imaging system (Fujifilm, Tokyo, Japan), and GAPDH level served as an internal control.

\subsection{Small-interference RNA (siRNA) transfection of PPAR}

A siRNA strategy was employed to silence PPAR $\alpha$ in THP-1 cells. Briefly, THP-1 cells were seeded onto 12-well or 6-well plates and cultured for $24 \mathrm{~h}$ in fresh medium without antibiotics. Then, the cells were transfected with PPAR $\alpha$ siRNA or NC siRNA (negative control) for $24 \mathrm{~h}$ using Lipofectamine ${ }^{\circledR}$ RNAiMAX reagent (Life Technologies ${ }^{\mathrm{TM}}$, USA), according to the manufacturer's instructions. After transfection, the cells were pretreated with $100 \mu \mathrm{M}$ N15 for $1 \mathrm{~h}$ before stimulation with LPS. Total cellular RNA was extracted, and qPCR performed $12 \mathrm{~h}$ after stimulation. Additionally, total cellular protein was extracted $24 \mathrm{~h}$ after stimulation, and the samples were analyzed by western blotting. A transfection rate of $60-70 \%$ of cells was achieved for all the experiments.

\subsection{Immunofluorescence assay}

THP-1 cells were attached to glass slides coated with L-lysine using a cytocentrifuge (Xiangyi, China). For immunofluorescence analysis, the cells were fixed with ice cold 4\% paraformaldehyde in PBS for $15 \mathrm{~min}$ at room temperature, washed thrice for 5 min with PBS, and then incubated with $10 \%$ goat serum blocking solution for $120 \mathrm{~min}$ at room temperature. After an overnight incubation with the primary antibody (p65 polyclonal antibody diluted $1: 100$ ) at $4^{0} \mathrm{C}$, the cells were washed thrice 
with PBS, and incubated with secondary antibody (Alex 594-conjugated goat anti-rabbit antibody, Invitrogen, USA). The slides were protected from light and incubated $60 \mathrm{~min}$ at room temperature. The cells were then washed thrice with PBS. The nuclei were stained with DAPI (100 ng/ml, Beyotime Biotechnology, China), and the samples were washed thrice with PBS. The slides were then mounted with anti-fade mounting medium (Beyotime Biotechnology, China), and observed under a confocal microscopy (Olympus FV1000, Tokyo, Japan).

\subsection{Statistical analysis}

The results are expressed as the mean \pm S.D. Statistical analysis was performed using one-way analysis of variance (ANOVA) for the differences within treatments, followed by Student-Newman-Keuls test for comparisons between two groups (Prism 5 for Windows, GraphPad Software Inc., USA). $P<0.05$ was considered to be statistically significant.

\section{Results}

\subsection{Effects of N15 and fenofibrate on cell viability}

The cytotoxicity of N15 and fenofibrate was evaluated using the MTS assay. Cell viability was unaffected by either N15 at concentrations between $10 \mu \mathrm{M}$ and 150 $\mu \mathrm{M}$ or fenofibrate at concentrations between $20 \mu \mathrm{M}$ and $150 \mu \mathrm{M}$ for $24 \mathrm{~h}$. These results exclude the potential cytotoxic effects of N15 or fenofibrate (Fig. 1). 
3.2. N15 inhibits the mRNA expression of chemokines and proinflammatory cytokines in LPS-stimulated THP-1 cells

In order to verify the inhibitory effect of N15 on inflammatory responses stimulated by LPS, the mRNA expression of some proinflammatory cytokines, such as TNF- $\alpha$, IL-1 $\beta$ and IL-6, and chemokines, such as IL-8, IP-10 and MCP-1, were evaluated using qPCR. The stimulation of THP-1 cells with LPS markedly increased TNF- $\alpha$, IL-1 $\beta$, IL-6, IL-8, IP-10 and MCP-1 mRNA expression. Notably, N15 and fenofibrate attenuated the expression of these mRNAs (Fig. 2). Of interest, when used at the same concentration of $100 \mu \mathrm{M}$ in LPS-stimulated THP-1 cells, the inhibitory effects of N15 on the chemokines, IL-8, IP-10 and MCP-1, were much better than that of fenofibrate $(P<0.001$ for all cytokines).

\subsection{N15 inhibits VCAM, MMP-2 and MMP-9 protein production}

MCP-1 is not only a chemokine, but is also an adhesion molecule. In addition to MCP-1, VCAM is also an important protein that regulates the adhesion of monocytes. MMP2 and MMP9, which are mainly produced from monocytes/macrophages, can degrade extracellular matrix components, such as collagens and elastins, resulting in the destabilization of atherosclerotic plaques (Lijnen, 2002). In order to clarify the effect of N15 on VCAM, MMP-2 and MMP-9 production, their protein levels were evaluated using western blotting.

A remarkable increase in the levels of VCAM, MMP-2 or MMP-9 protein was observed in THP-1 cells stimulated with LPS, and the levels of these proteins were all 
reduced in a dose-dependent manner following N15 treatment (Fig. 3). Of note, when used at the same concentration of $100 \mu \mathrm{M}$, the inhibitory effects of N15 on VCAM, MMP2 and MMP9 were greater than that of fenofibrate $(P<0.001, P<0.001$ and $P<$ 0.05, respectively) in LPS-stimulated THP-1 cells (Fig. 3).

\subsection{N15 activates PPAR in LPS-induced THP-1 cells}

In our previous study, N15 was shown to promote the trans-activation of PPAR $\alpha$ in HeLa cells (Chen et al., 2015), but whether it could also activate PPAR $\alpha$ in THP-1 cells needs verifying. Our results showed that N15 was able to promote PPAR $\alpha$ protein expression in a dose-dependent manner (Fig. 4A and B). Moreover, the increase in PPAR $\alpha$ protein expression induced by N15 was almost twice of that induced by the same concentration $(100 \mu \mathrm{M})$ of fenofibrate in LPS-stimulated THP-1 cells. The mRNA levels of CD36 and UCP-2 (Fig. 4C and D), which are downstream of PPAR $\alpha$ (Fu et al., 2005), were also consistent with the changes in PPAR $\alpha$ protein levels.

3.5. The inhibitory effect of N15 on inflammatory responses in LPS-stimulated THP-1 cells is dependent on PPARa activation

To define the role of PPAR $\alpha$ in the anti-inflammatory effects of N15, THP-1 cells were transfected with PPAR $\alpha$ siRNA before treatment with N15 and were subsequently stimulated with LPS. As shown in Fig. 5A, N15 decreased LPS-induced IL-6 production in the negative control, but this effect was abrogated in PPAR $\alpha$ 
siRNA cells, indicating that the inhibitory effect of N15 on IL-6 gene expression in THP-1 cells was dependent on PPAR $\alpha$. Similar results were also observed for MCP-1, IP-10 and IL-8 (Fig. 5B, C and D). These data demonstrated that N15 inhibited the inflammatory responses in LPS-induced THP-1 cells through PPAR $\alpha$ activation.

3.6. N15 attenuates the TLR4/NF- $\kappa B$ and STAT3 inflammatory signaling pathways in LPS-stimulated THP-1 cells through PPARa activation

It is well established that the activation of TLR4 by LPS (Hume et al., 2001) triggers the production of pro-inflammatory cytokines (Kagan and Medzhitov, 2006) and chemokines (Tsai et al., 2014) via NF-אB activation (Luo et al., 2015). To test whether N15 affected the classical TLR4/NF- $\kappa$ B inflammatory signaling pathway induced by LPS, TLR4 and NF-kB p65 protein levels were measured by western blotting. As shown in Fig. 6A, B and C, LPS markedly induced an increase in TLR4 levels and the phosphorylation of p65, and treatment of N15 attenuated both TLR4 and p-p65 in a dose-dependent manner, suggesting that N15 has an inhibitory effect on the TLR4/NF- $\mathrm{B}$ inflammatory signaling pathway induced by LPS.

STAT3 tyrosine phosphorylation is critical for monocyte chemotaxis and migration (Jougasaki et al., 2010), as well as for IL-6 and IL-1 $\beta$ production(Samavati et al., 2009) in response to LPS. In order to clarify whether N15 prevents the phosphorylation of STAT3, the protein level of p-STAT3 was evaluated using western blotting. As shown in Fig. 6D and E, LPS markedly induced the phosphorylation of STAT3, and treatment with N15 suppressed the phosphorylation 
of STAT3 in a dose-dependent manner, demonstrating the possible involvement of STAT3 suppression in the anti-inflammatory effect of N15.

However, although fenofibrate exhibited inhibitory effects on TLR4/ NF- $\kappa \mathrm{B}$ and p-STAT3 protein levels, the effects were not significant and were considerably weaker than that observed when cells were treated with the same concentration (100 $\mu \mathrm{M})$ of N15 $(P<0.001$ in the case of either TLR4, p-p65 or p-STAT3) (Fig. 6).

Because PPAR $\alpha$ interferes with the nuclear translocation of p65 (Bak et al.,

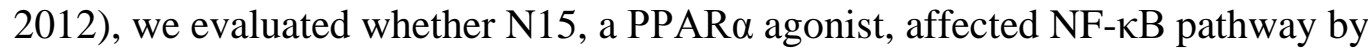
regulating p65 translocation. Our immunofluorescence results showed that LPS stimulation resulted in the nuclear import of p65, while N15 treatment prevented p65 from entering the nucleus (Fig. 7).

Taken together, our results showed that N15 attenuates the TLR4/NF- $\kappa \mathrm{B}$ and STAT3 inflammatory signaling pathways in LPS-stimulated THP-1 cells. In order to define whether the inhibitory effect of N15 on the TLR4/NF- $\mathrm{KB}$ and STAT3 pathways occurred via PPAR $\alpha$ activation, the protein levels of TLR4, p-p65 and p-STAT3 were assessed after PPAR $\alpha$ was silenced by siRNA transfection. As shown in Fig. 8, PPAR $\alpha$ siRNA reversed the attenuation of TLR4, p-p65 and p-STAT3 caused by N15, suggesting a PPAR $\alpha$-dependent inhibitory effect of N15 on the TLR4/NF-kB and STAT3 pathways.

\section{Discussion}


Atherosclerosis is considered a chronic inflammatory disease of the vessel walls (Farhat et al., 2013). Monocyte/macrophages are important players in the inflammatory process of this disease (Zhang et al., 2014), and the activation of the monocyte/macrophages by LPS leads to the increased secretion of several proinflammatory cytokines, such as TNF- $\alpha$, IL-1 $\beta$, IL-6 and MMPs (Christensen et al., 2015). Persistent production of these proinflammatory cytokines can cause severe vascular destruction and eventually atherosclerosis. MMPs not only contribute to the progression of atherosclerotic plaques due to their proinflammatory effects but also cause plaque destabilization by degrading components of the extracellular matrix. In addition, atherosclerotic inflammation involves the recruitment of monocytes during all phases of the disease. Chemokines, such as MCP-1, IL-8 and IP-10 (Mukaida et al., 1998), and adhesion molecules are instrumental in orchestrating the influx of monocytes to the vascular wall (Zernecke and Weber, 2010).

There is mounting evidence that PPAR $\alpha$ plays a role in inflammation control, as well as lipid regulation. PPAR $\alpha$ activators exert their anti-inflammatory activities in different vascular wall cell types, such as monocyte/macrophages, endothelial and smooth muscle cells, in which PPAR $\alpha$ are expressed (Chinetti et al., 2000).

N15 is a novel PPAR $\alpha$ agonist that was synthesized in our laboratory. It is an analogue of the PPAR $\alpha$ endogenous ligand, OEA, but is resistant to enzymatic hydrolysis and therefore has more stable chemical properties compared to OEA. In the present study, we investigated the anti-inflammatory effect of N15 in THP-1 cells in response to LPS, which is commonly used for inducing inflammation 
(Frede et al., 2006; Tsai et al., 2015). Additionally, we compared the difference between N15 and fenofibrate, the mostly common used PPAR $\alpha$ agonist in the clinic, with respect to their anti-inflammatory effects and the underlying molecular mechanisms.

Based on our results, we drew four main conclusions.

First, N15 has remarkable inhibitory effects on LPS-induced inflammatory responses in THP-1 cells. Three aspects of the anti-inflammatory effects of N15 were evaluated, the expression of proinflammatory cytokine mRNA, the expression of chemokine mRNA and the expression of VCAM and MMPs protein. N15 notably inhibited the expression of all these inflammatory markers in THP-1 cells stimulated with LPS (Fig. 2 and Fig. 3).

Second, PPAR $\alpha$ activation was found to be responsible for the anti-inflammatory effect of N15. Because N15 was designed to target the spatial structure of PPAR $\alpha$ protein, and its ability to activate PPAR $\alpha$ was previously shown in Hela cells (Chen et al., 2011), we hypothesized that its anti-inflammatory effect in THP-1 cells would also be dependent on PPAR $\alpha$ activation. The hypothesis was verified in the two following ways: (1) N15 treatment increased PPAR $\alpha$ protein levels and PPAR $\alpha$ downstream genes in THP-1 cells (Fig. 4); (2) PPAR $\alpha$ silencing using siRNA reversed the anti-inflammatory effect of N15 (Fig. 5). Thus, the above evidence demonstrates that the inhibitory effect of N15 on LPS-induced inflammatory responses in THP-1 cells is dependent on PPAR $\alpha$ activation.

Third, the inhibition of TLR4/NF- $\mathrm{BB}$ and STAT3 is also involved in the 
mechanism by which N15 exerts its anti-inflammatory effect in THP-1 cells in response to LPS. PPAR $\alpha$ activators have been shown to inhibit the activation of inflammatory response genes, such as IL-6, IL-8, TNF $\alpha$ and MMPs, by negatively

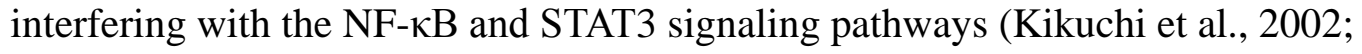
Roglans et al., 2007). Consistently, our results showed that N15 inhibited TLR4/NF- $\kappa$ B and STAT3 signaling pathways in a PPAR $\alpha$-dependent manner (Fig. 6, Fig. 7 and Fig. 8), suggesting the involvement of TLR4/NF-אB and STAT3 inhibition in the anti-inflammatory effect of N15.

Finally, N15 is superior to fenofibrate, a clinically used PPAR $\alpha$ agonist, in terms of its ability to inhibit inflammation in LPS-stimulated THP-1 cells. N15 showed some advantages over fenofibrate especially with respect to altering the expression of chemokine mRNAs and VCAM and MMPs proteins (Fig. 2 and Fig. 3). These advantages might result from the more potent PPAR $\alpha$ activation (Fig. 4) and TLR4/NF- $\kappa$ B and STAT3 inhibition caused by N15 treatment, compared with fenofibrate treatment (Fig. 6). In addition, because N15 treatment reduces chemokine mRNA expressions and VCAM protein expression more extensively than fenofibrate, it is possible that, compared to fenofibrate, anti-atherogenic therapy with N15 may decrease monocyte recruitment to the plaque and better increase plaque stability. This requires further investigation in future in vivo studies.

In conclusion, as a novel PPAR $\alpha$ agonist, N15 exerts an anti-inflammatory effect that is dependent on PPAR $\alpha$ activation and TLR4/NF- $\mathrm{BB}$ and STAT3 inhibition and exhibits several advantages over fenofibrate with respect to inflammation control in 
LPS-stimulated THP-1 cells. Our study suggests that N15 is promising for alleviating atherosclerosis.

\section{Conflict of Interests}

The authors have no conflicts of interest concerning this work.

\section{Acknowledgments}

This study was supported by grants from the National Natural Science

Foundation of China (Grant No. 81373407) and the Natural Science Foundation of Fujian Province (Grant No. 2016J05204).

\section{References}

Bak, M.J., Hong, S.G., Lee, J.W., Jeong, W.S., 2012. Red ginseng marc oil inhibits iNOS and COX-2 via NFkappaB and p38 pathways in LPS-stimulated RAW 264.7 macrophages. Molecular 17, 13769-13786.

Chawla, A., 2010. Control of macrophage activation and function by PPARs. Circ. Res. 106, 1559-1569.

Chen, C.X., Jin, X., Meng, X.L., Zheng, C.W., Shen, Y.H., Wang, Y.Q., 2011. Inhibition of TNF

alpha-induced adhesion molecule expression by (Z)-(S)-9-octadecenamide,

N-(2-hydroxyethyl,1-methyl). Eur. J. Pharmacol. 660, 305-309.

Chen, C.X., Yang, L.C., Xu, X.D., Wei, X., Gai, Y.T., Peng, L., Guo, H., Hao, Z., Wang, Y.Q., Jin, X., 2015.

Effect of propane-2-sulfonic acid octadec-9-enyl-amide on the expression of adhesion molecules in 
human umbilical vein endothelial cells. Eur. J. Pharmacol. 756, 15-21.

Chen, Y., Hu, Y., Lin, M., Jenkins, A.J., Keech, A.C., Mott, R., Lyons, T.J., Ma, J.X., 2013. Therapeutic effects of PPARalpha agonists on diabetic retinopathy in type 1 diabetes models. Diabetes 62,

261-272.

Chinetti, G., Fruchart, J.C., Staels, B., 2000. Peroxisome proliferator-activated receptors (PPARs):

Nuclear receptors at the crossroads between lipid metabolism and inflammation. Inflamm. Res. 49,

497-505.

Christensen, M.H.E., Fenne, I.S., Nordbo, Y., Varhaug, J.E., Nygard, K.O., Lien, E.A., Mellgren, G., 2015.

Novel inflammatory biomarkers in primary hyperparathyroidism. Eur. J. Endocrinol. 173, 9-17.

Farhat, N., Thorin-Trescases, N., Mamarbachi, M., Villeneuve, L., Yu, C., Martel, C., Duquette, N., Gayda, M., Nigam, A., Juneau, M., Allen, B.G., Thorin, E., 2013. Angiopoietin-Like 2 Promotes Atherogenesis in Mice. J. Am. Heart Assoc. 2.

Fernandez, A.Z., 2008. Peroxisome proliferator-activated receptors in the modulation of the immune/inflammatory response in atherosclerosis. PPAR Res. 2008, 285842.

Frede, S., Stockmann, C., Freitag, P., Fandrey, J., 2006. Bacterial lipopolysaccharide induces HIF-1 activation in human monocytes via p44/42 MAPK and NF-kappa B. Biochem. J. 396, 517-527. Fu, J., Astarita, G., Gaetani, S., Kim, J., Cravatt, B.F., Mackie, K., Piomelli, D., 2007. Food intake regulates oleoylethanolamide formation and degradation in the proximal small intestine. J. Bio. Chem. 282, 1518-1528.

Fu, J., Kim, J., Oveisi, F., Astarita, G., Piomelli, D., 2008. Targeted enhancement of oleoylethanolamide production in proximal small intestine induces across-meal satiety in rats. Am. J. Physiol. Regul. Integr. Comp. Physiol. 295, R45-50. 
Fu, J., Oveisi, F., Gaetani, S., Lin, E., Piomelli, D., 2005. Oleoylethanolamide, an endogenous

PPAR-alpha agonist, lowers body weight and hyperlipidemia in obese rats. Neuropharmacology 48,

1147-1153.

Hume, D.A., Underhill, D.M., Sweet, M.J., Ozinsky, A.O., Liew, F.Y., Aderem, A., 2001. Macrophages

exposed continuously to lipopolysaccharide and other agonists that act via toll-like receptors exhibit a sustained and additive activation state. BMC Immunol. 2, 11.

Jougasaki, M., Ichiki, T., Takenoshita, Y., Setoguchi, M., 2010. Statins suppress interleukin-6-induced monocyte chemo-attractant protein-1 by inhibiting Janus kinase/signal transducers and activators of transcription pathways in human vascular endothelial cells. Br. J. Pharmacol. 159, 1294-1303.

Kagan, J.C., Medzhitov, R., 2006. Phosphoinositide-mediated adaptor recruitment controls Toll-like receptor signaling. Cell 125, 943-955.

Khera, A.V., Millar, J.S., Ruotolo, G., Wang, M.D., Rader, D.J., 2015. Potent peroxisome proliferator-activated receptor-alpha agonist treatment increases cholesterol efflux capacity in humans with the metabolic syndrome. Eur. Heart J. 36, 3020-3022.

Kikuchi, T., Hagiwara, K., Honda, Y., Gomi, K., Kobayashi, T., Takahashi, H., Tokue, Y., Watanabe, A., Nukiwa, T., 2002. Clarithromycin suppresses lipopolysaccharide-induced interleukin-8 production by human monocytes through AP-1 and NF-kappa B transcription factors. J. Antimicrob. Chemoth. 49, 745-755.

Lijnen, H.R., 2002. Extracellular proteolysis in the development and progression of atherosclerosis. Biochem. Soc. T. 30, 163-167.

Luo, H., Wang, J., Qiao, C., Ma, N., Liu, D., Zhang, W., 2015. Pycnogenol attenuates atherosclerosis by regulating lipid metabolism through the TLR4-NF-kappaB pathway. Exp. Mol. Med. 47, e191. 
Mukaida, N., Harada, A., Matsushima, K., 1998. Interleukin-8 (IL-8) and monocyte chemotactic and activating factor (MCAF/MCP-1), chemokines essentially involved in inflammatory and immune reactions. Cytokine Growth Factor Rev. 9, 9-23.

Pang, T., Benicky, J., Wang, J., Orecna, M., Sanchez-Lemus, E., Saavedra, J.M., 2012. Telmisartan ameliorates lipopolysaccharide-induced innate immune response through peroxisome proliferator-activated receptor-gamma activation in human monocytes. J. Hypertens. 30, 87-96. Roglans, N., Vila, L., Farre, M., Alegret, M., Sanchez, R.M., Vazquez-Carrera, M., Laguna, J.C., 2007. Impairment of hepatic Stat-3 activation and reduction of PPARalpha activity in fructose-fed rats. Hepatology 45, 778-788.

Samavati, L., Rastogi, R., Du, W., Huttemann, M., Fite, A., Franchi, L., 2009. STAT3 tyrosine phosphorylation is critical for interleukin 1 beta and interleukin- 6 production in response to lipopolysaccharide and live bacteria. Mol. Immunol. 46, 1867-1877.

Schafer, H.L., Linz, W., Falk, E., Glien, M., Glombik, H., Korn, M., Wendler, W., Herling, A.W., Rutten, H., 2012. AVE8134, a novel potent PPARalpha agonist, improves lipid profile and glucose metabolism in dyslipidemic mice and type 2 diabetic rats. Acta Pharmacol. Sin. 33, 82-90.

Tsai, J.H., Kuo, C.H., Yang, P., Cheng, K.H., Wang, P.W., Chen, C.C., Hung, C.H., 2014. Effects of antidepressants on IP-10 production in LPS-activated THP-1 human monocytes. Int. J. Mol. Sci. 15, 13223-13235.

Tsai, M.K., Hsieh, C.C., Kuo, H.F., Lee, M.S., Huang, M.Y., Kuo, C.H., Hung, C.H., 2015. Effect of prostaglandin 12 analogs on monocyte chemoattractant protein-1 in human monocyte and macrophage. Clin. Exp. Med. 15, 245-253.

Varga, T., Czimmerer, Z., Nagy, L., 2011. PPARs are a unique set of fatty acid regulated transcription 
factors controlling both lipid metabolism and inflammation. Biochimi. Biophys. Acta 1812, 1007-1022.

Zernecke, A., Weber, C., 2010. Chemokines in the vascular inflammatory response of atherosclerosis.

Cardiovasc. Res. 86, 192-201.

Zhang, X.X., Wang, G.J., Gurley, E.C., Zhou, H.P., 2014. Flavonoid Apigenin Inhibits

Lipopolysaccharide-Induced Inflammatory Response through Multiple Mechanisms in Macrophages.

PloS one 9. 


\section{Figures}

Fig. 1. Effects of N15 and fenofibrate on cell viability. THP-1 cells were treated with or without N15 or fenofibrate at different concentrations for $24 \mathrm{~h}$. Then, MTS was added and cell viability was evaluated. (A) Effects of N15 on cell viability. (B) Effects of fenofibrate on cell viability.

Fig. 2. Effects of N15 on the mRNA expression of proinflammatory cytokines and chemokines. (A)-(F) THP-1 cells were pretreated with fenofibrate $(100 \mu \mathrm{M})$ or N15 $(20,50$ and $100 \mu \mathrm{M})$ for $1 \mathrm{~h}$ before stimulation with LPS $(1 \mu \mathrm{g} / \mathrm{ml})$ for $12 \mathrm{~h}$. The effects of N15 on the mRNA expression of IL-6, TNF- $\alpha$, IL-1 $\beta$, IL-8, IP-10 and MCP-1 were evaluated using qPCR. The values are expressed as the mean \pm S.D. of triplicate assays. ${ }^{\# \#} P<0.001$ vs. control, ${ }^{*} P<0.05,{ }^{* *} P<0.01$ and ${ }^{* * * *} P<0.001$ vs. LPS.

Fig. 3. Effects of N15 on the protein levels of VCAM, MMP2 and MMP9. THP-1 cells were pretreated with fenofibrate $(100 \mu \mathrm{M})$ or $\mathrm{N} 15(20,50$ and $100 \mu \mathrm{M})$ for $1 \mathrm{~h}$ before stimulation with LPS $(1 \mu \mathrm{g} / \mathrm{ml})$ for $24 \mathrm{~h}$. The protein levels of VCAM, MMP2 and MMP9 were evaluated using western blotting. (A) The experiments were repeated three times, and similar results were obtained. Representative immunoblots for VCAM are shown. (B) For the quantitation of the proteins of interest, the band intensities of VCAM were converted to arbitrary densitometric units and normalized to the value of GAPDH. (C) Representative immunoblots for MMP2 and MMP9 are shown. (D)-(E) The band intensities of MMP2 and MMP9 were converted to arbitrary 
densitometric units and were normalized to the value of GAPDH. The values are expressed as the mean \pm S.D. of triplicate assays. ${ }^{\# \#} P<0.01$ and ${ }^{\# \#} P<0.001$ vs. control, ${ }^{* *} P<0.01$ and ${ }^{* * *} P<0.001$ vs. LPS.

Fig. 4. Effects of N15 on PPAR $\alpha$ activation in THP-1 cells. (A) THP-1 cells were pretreated with fenofibrate $(100 \mu \mathrm{M})$ or N15 $(20,50$ and $100 \mu \mathrm{M})$ for $1 \mathrm{~h}$ before stimulation with LPS $(1 \mu \mathrm{g} / \mathrm{ml})$ for $24 \mathrm{~h}$. The experiments were repeated three times, and similar results were obtained. Representative immunoblots for PPAR $\alpha$ are shown. (B) For the quantitation of the proteins of interest, the band intensities of PPAR $\alpha$ were converted to arbitrary densitometric units and were normalized to the value of GAPDH. (C)-(D) The mRNA levels of UCP-2 and CD36 after N15 $(100 \mu \mathrm{M})$ treatment were determined using qPCR. The values are expressed as the mean \pm S.D. of triplicate assays. ${ }^{\#} P<0.05$ and ${ }^{\# \#} P<0.01 v s$. control, ${ }^{*} P<0.05,{ }^{* *} P<0.01$ and ${ }^{* * *} P<0.001 v s$. LPS.

Fig. 5. Effect of N15 on the expression of cytokine mRNAs in PPAR $\alpha$ siRNA transfected THP-1 Cells. (A)-(D) THP-1 cells transfected with PPAR $\alpha$ or NC siRNA were treated with $\mathrm{N} 15(100 \mu \mathrm{M})$ for $1 \mathrm{~h}$ and/or stimulated with LPS $(1 \mu \mathrm{g} / \mathrm{ml})$ for $12 \mathrm{~h}$. The mRNA expressions of IL-6, MCP-1, IP-10 and IL-8 were evaluated using qPCR. The values are expressed as the mean \pm S.D. of triplicate assays. ${ }^{\# \#} P<0.001$ vs. control+NCsiRNA, ${ }^{* * *} P<0.001 v s$. LPS+NCsiRNA, and ${ }^{\wedge \wedge} P<0.01$ and ${ }^{\wedge \wedge} P<0.001 v s$. LPS+N15+NCsiRNA. 
Fig. 6. Effect of N15 on TLR4, p-p65 and p-STAT3 protein levels. THP-1 cells were pretreated with fenofibrate $(100 \mu \mathrm{M})$ or N15 $(20,50$ and $100 \mu \mathrm{M})$ for $1 \mathrm{~h}$ before stimulation with LPS ( $1 \mu \mathrm{g} / \mathrm{ml})$ for $24 \mathrm{~h}$. (A) The experiments were repeated three times, and similar results were obtained. Representative immunoblots for TLR4, p65 and p-p65 are shown. (B)-(C) For the quantitation of the proteins of interest, the band intensities of TLR4 and p-p65 were converted to arbitrary densitometric units and were normalized to the value of GAPDH. (D) Representative immunoblots for STAT3 and p-STAT3areshown. (E) The band intensities of p-STAT3 were converted to arbitrary densitometric units and were normalized to the value of GAPDH. The values are expressed as the mean \pm S.D. of triplicate assays. ${ }^{\# \#} P<0.001 \mathrm{vs}$. control, ${ }^{* *} P<0.01$ and ${ }^{* * *} P<0.001 v s$. LPS.

Fig. 7. Effect of N15 on the nuclear translocation of p65. THP-1 cells were pretreated with N15 $(100 \mu \mathrm{M})$ for $1 \mathrm{~h}$ before stimulation with LPS $(1 \mu \mathrm{g} / \mathrm{ml})$ for $24 \mathrm{~h}$. The cells were fixed and stained for immunofluorescence with antibodies against p65 (red). Nuclei were visualized with the nuclear dye DAPI (blue). Finally, cells were visualized and photographed using a confocal laser scanning microscope at $600 \times$ magnification.

Fig. 8. The inhibitory effect of N15 on the TLR4/NF- $\kappa$ B and STAT3 pathways occurs via PPAR $\alpha$ activation. THP-1 cells transfected with PPAR $\alpha$ or NC siRNA were 
pretreated with N15 $(100 \mu \mathrm{M})$ for $1 \mathrm{~h}$ before stimulation with LPS $(1 \mu \mathrm{g} / \mathrm{ml})$ for $24 \mathrm{~h}$. (A) The experiments were repeated three times, and similar results were obtained. Representative immunoblots for TLR4 are shown. (B) For the quantitation of the proteins of interest, the band intensities of TLR4 were converted to arbitrary densitometric units and were normalized to the value of GAPDH. (C) Representative immunoblots for p65, p-p65, STAT3 and p-STAT3 are shown. (D)-(E) The band intensities of p-p65 and p-STAT3 were converted to arbitrary densitometric units, and normalized to the value of GAPDH. The values are expressed as the mean \pm S.D. of triplicate assays. ${ }^{\# \#} P<0.001$ vs. control+NCsiRNA, ${ }^{* * *} P<0.001 v s$. LPS+NCsiRNA, and ${ }^{\wedge \wedge} P<0.001 v s$. LPS+N15+NCsiRNA. 
A

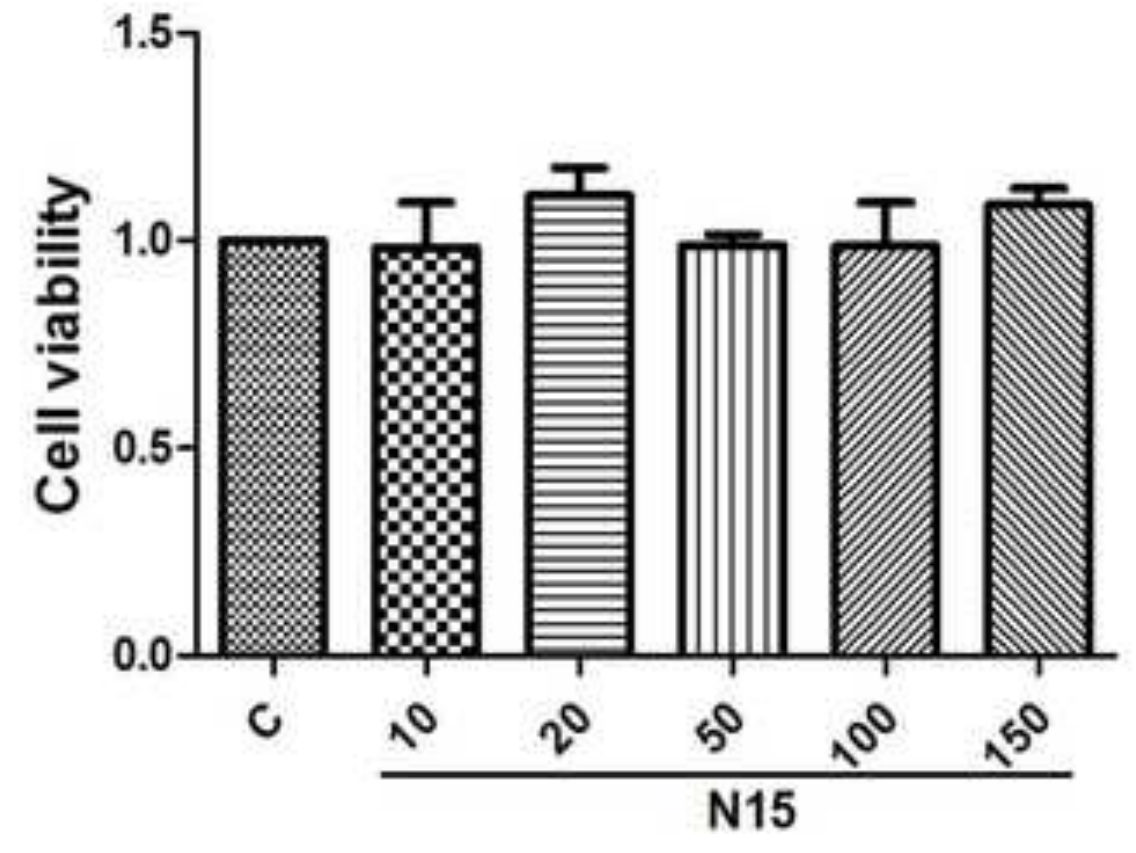

B

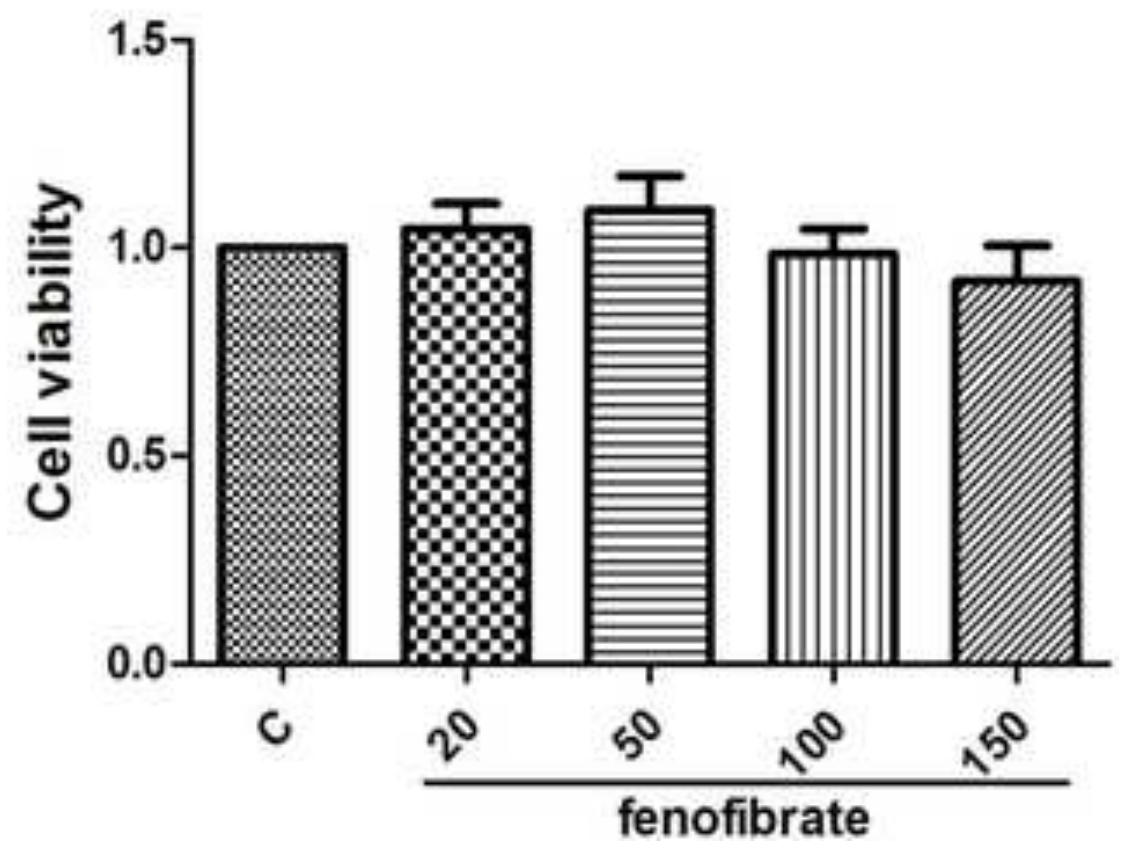


A

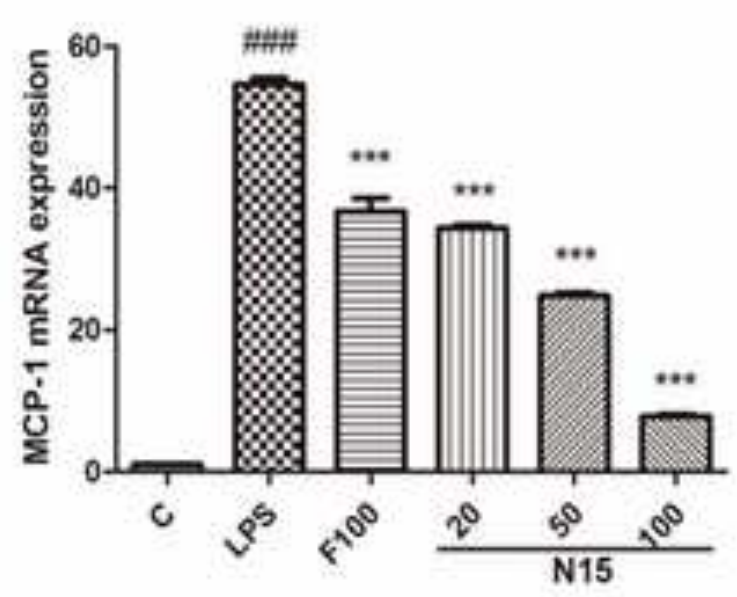

D

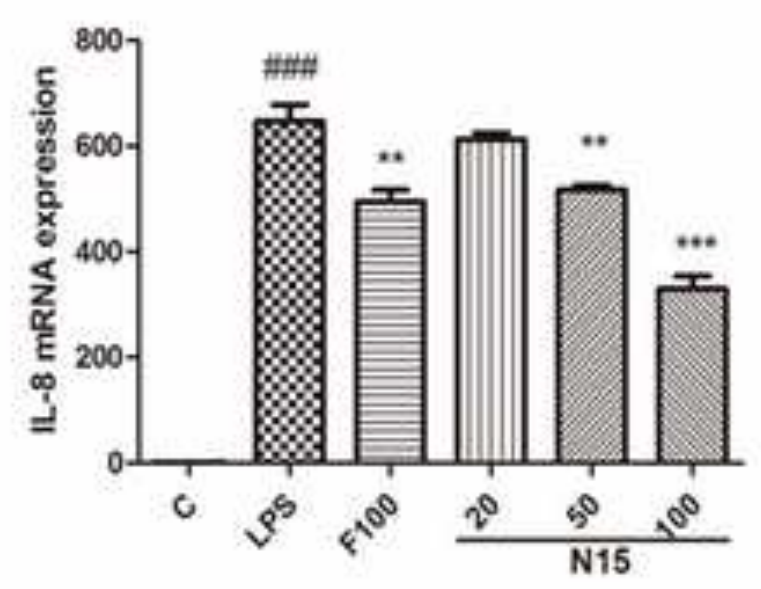

B

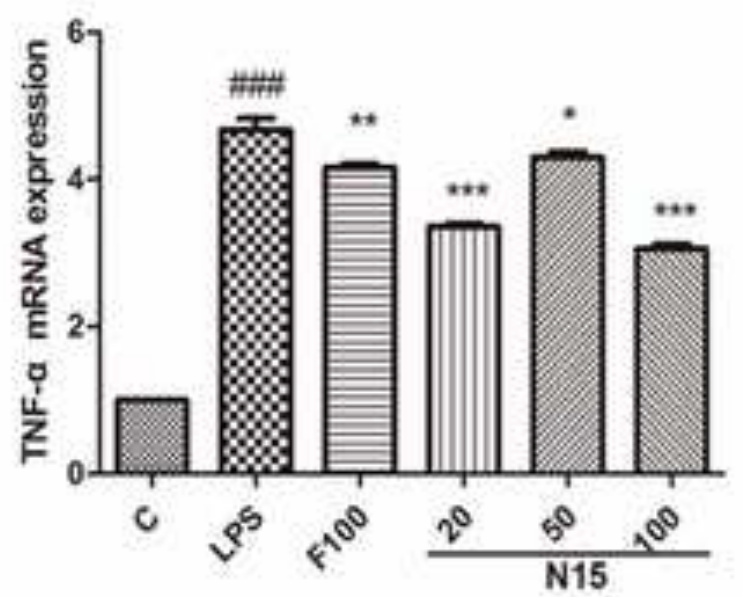

E

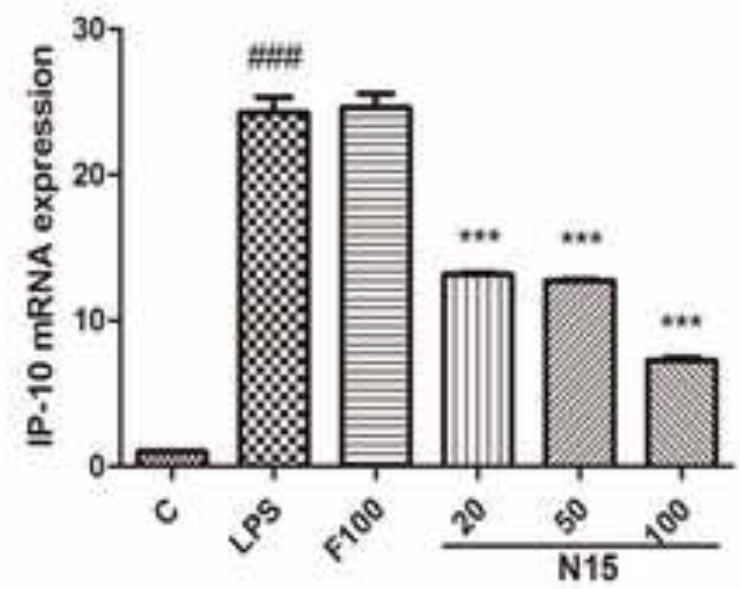

C

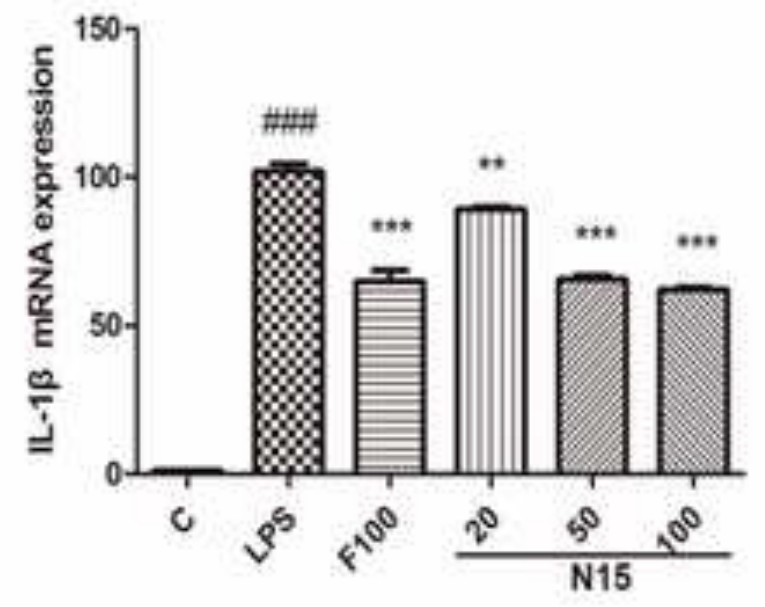

F

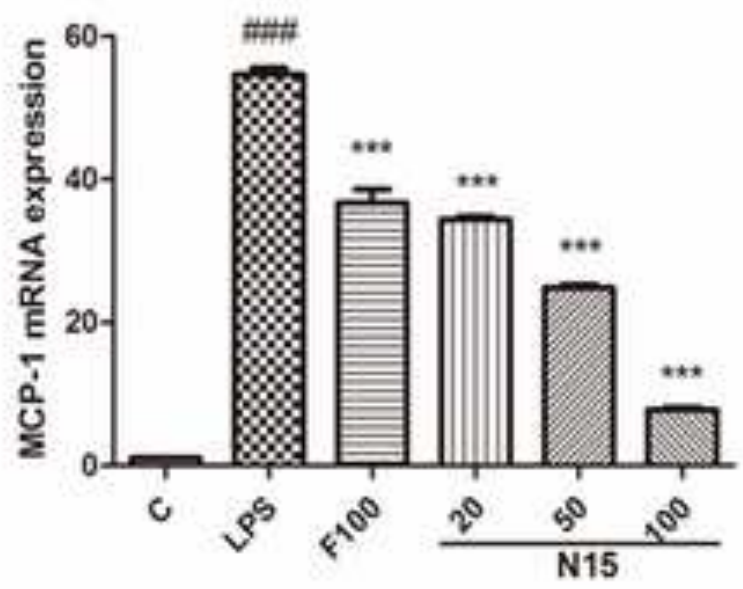



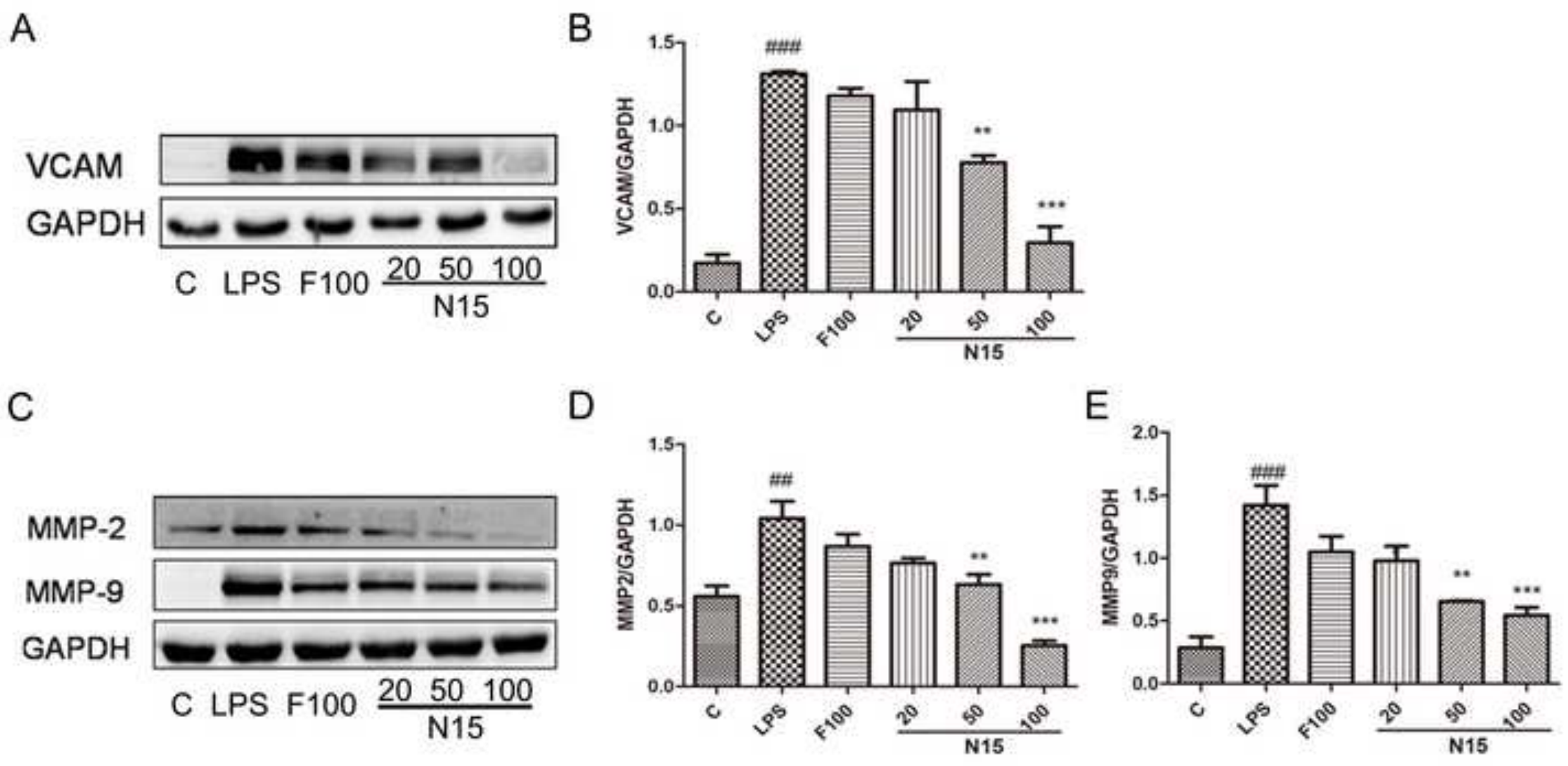
Figure 4

A

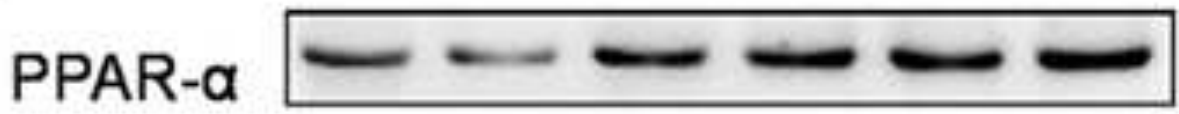
GAPDH

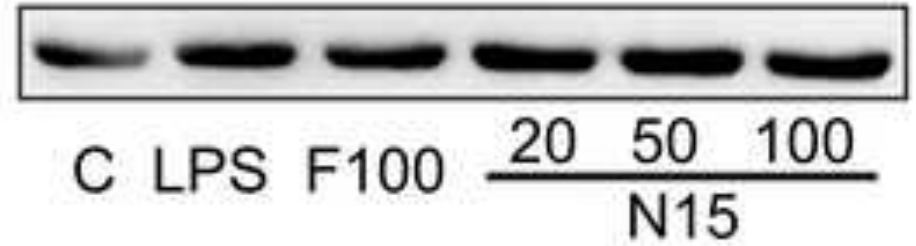

B

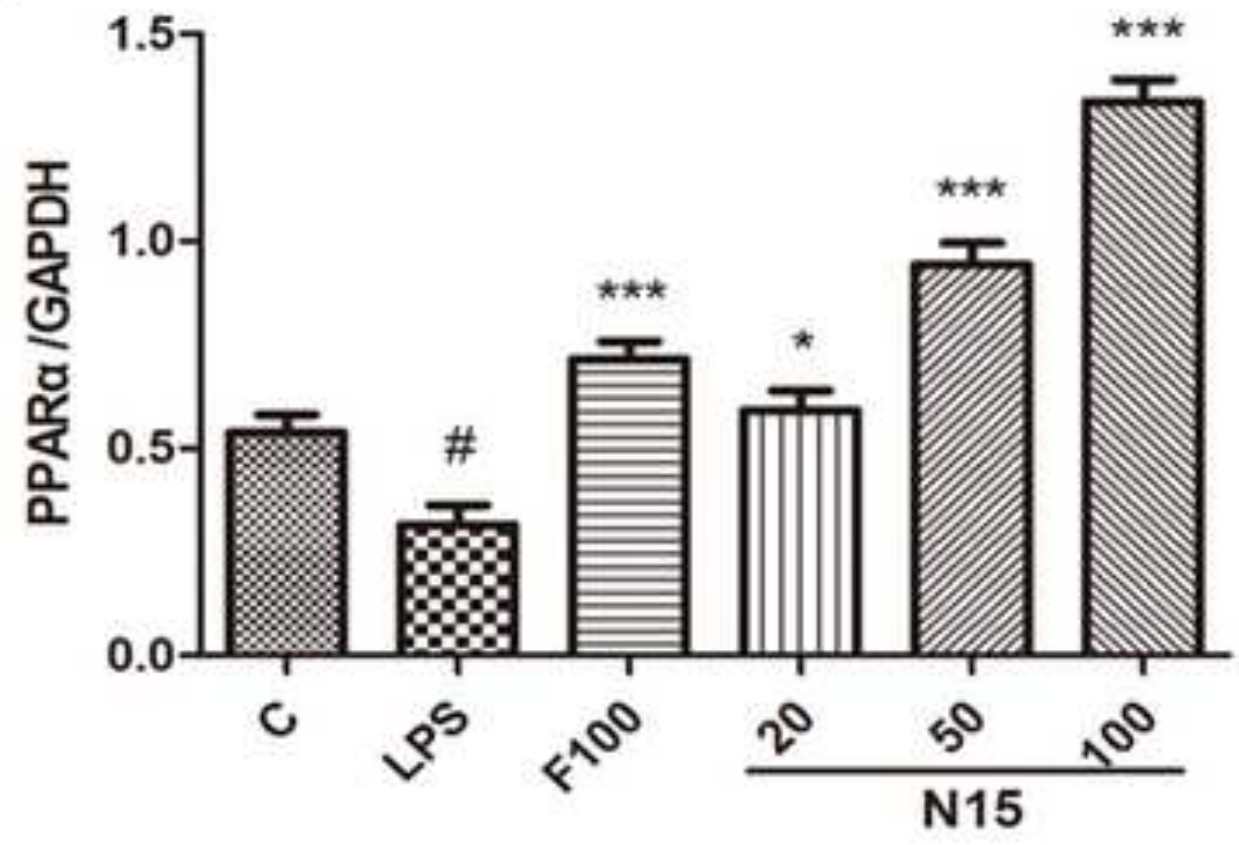

C

D
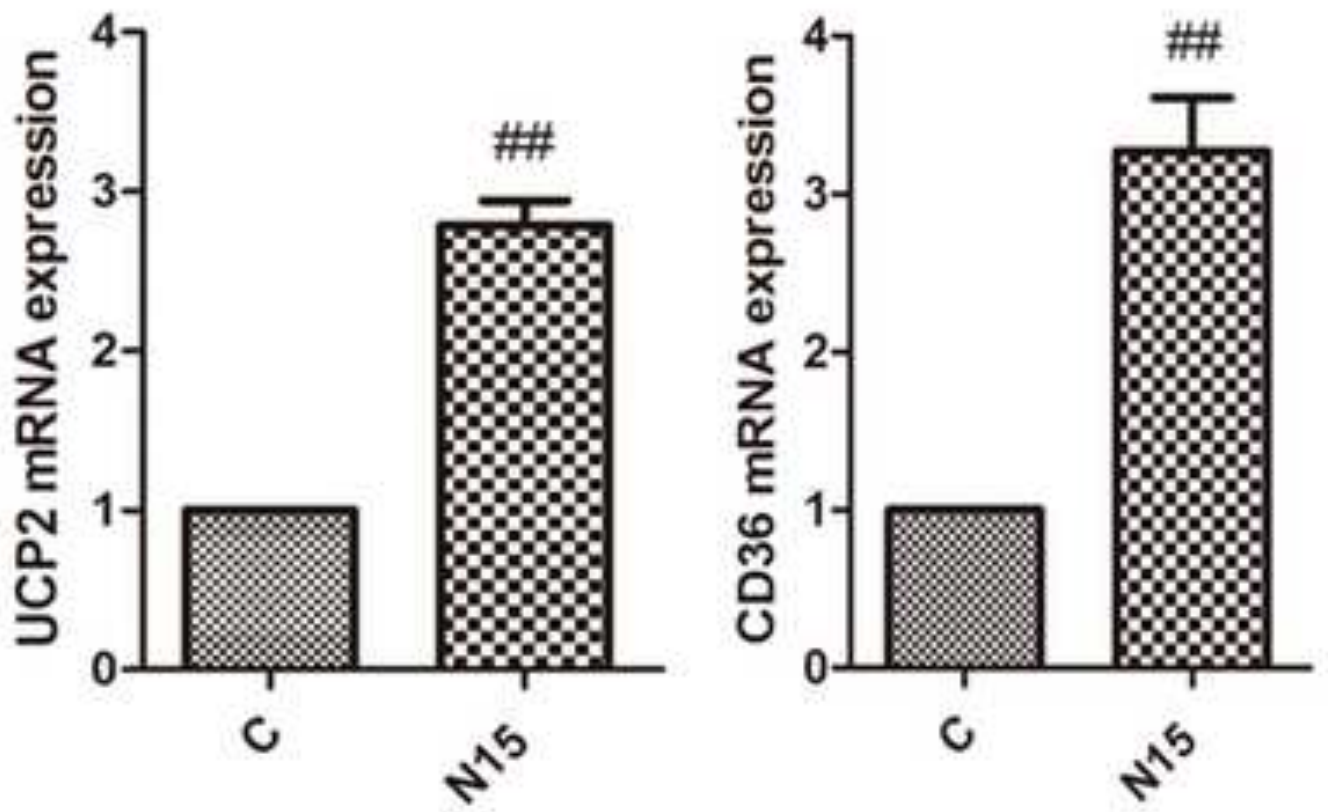
A

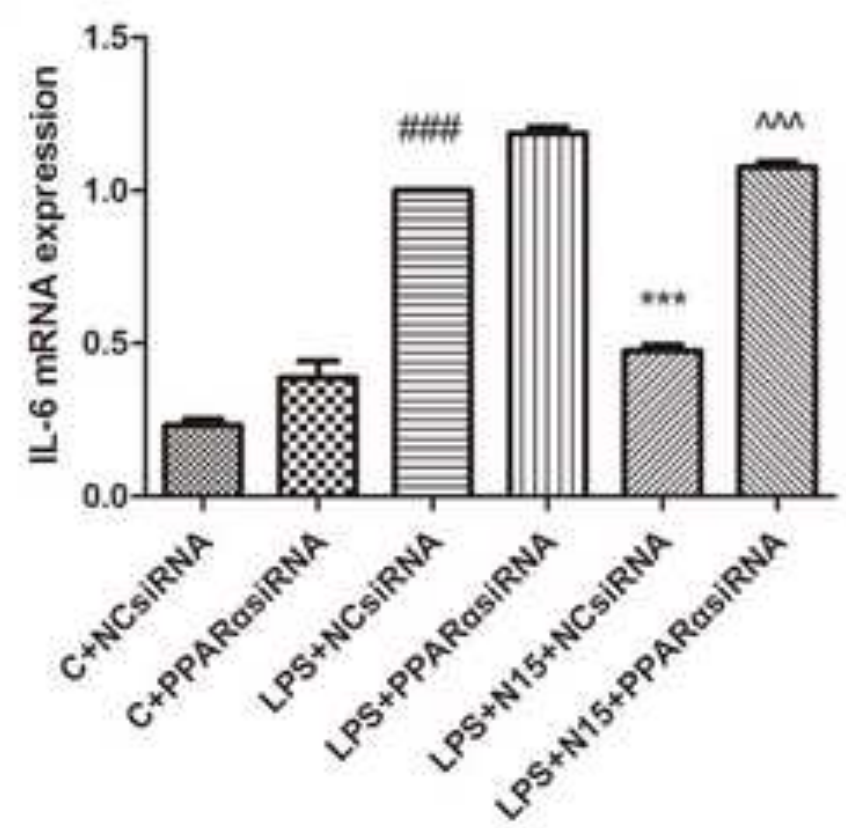

C

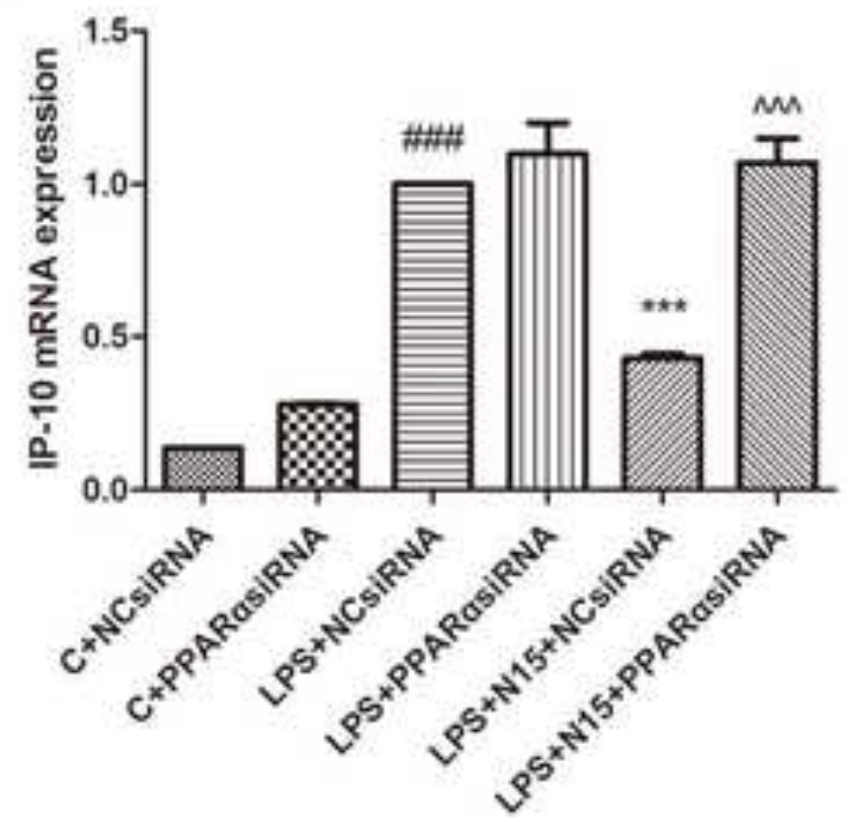

B

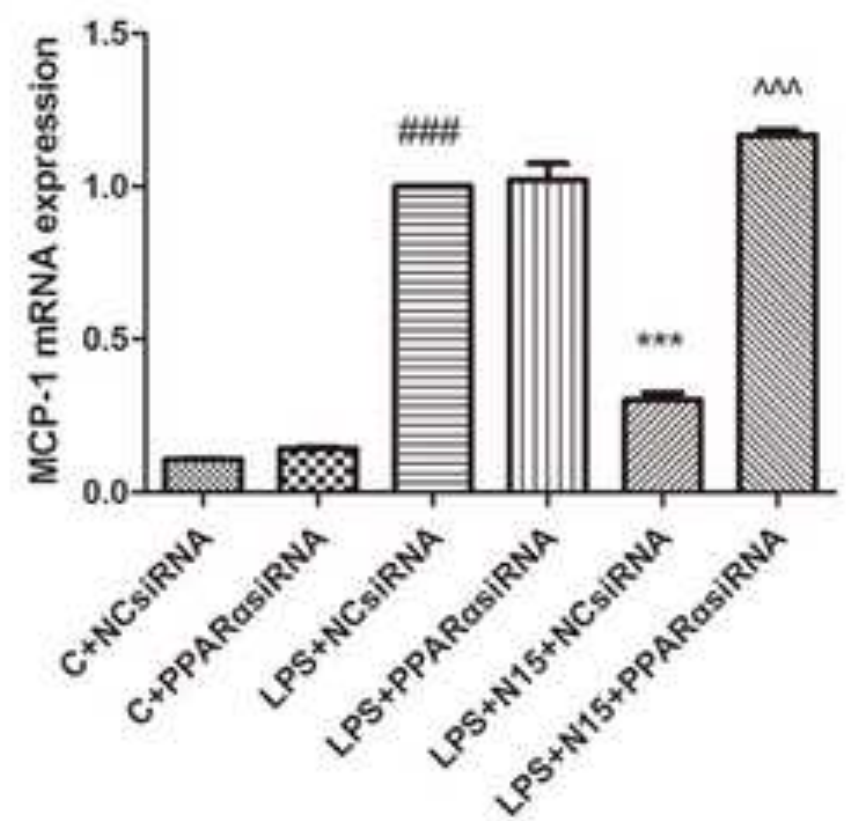

D

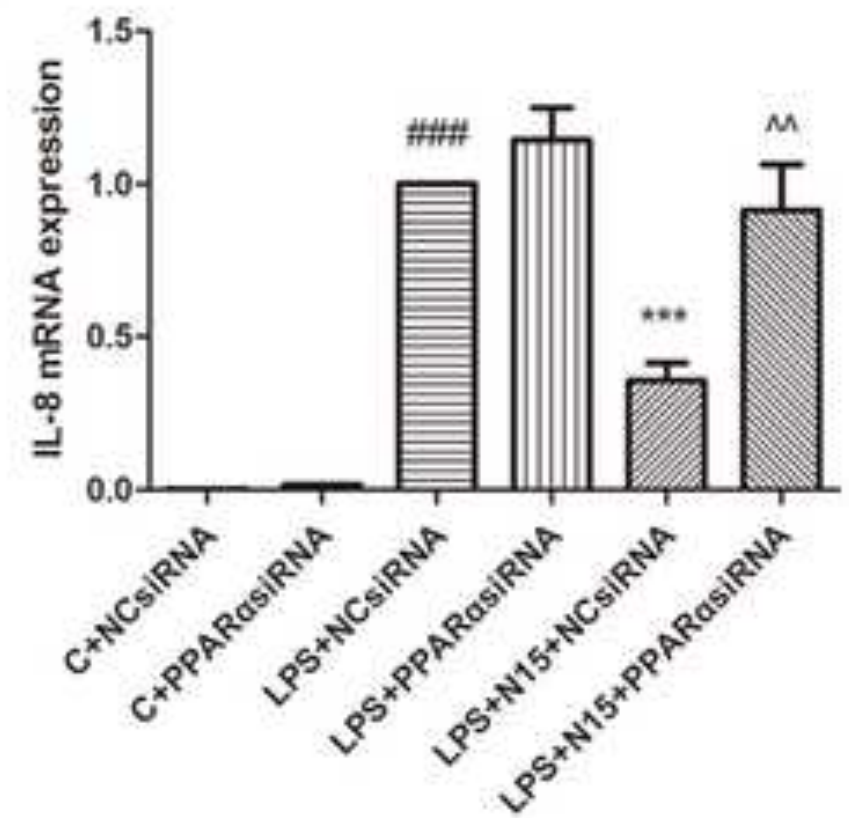




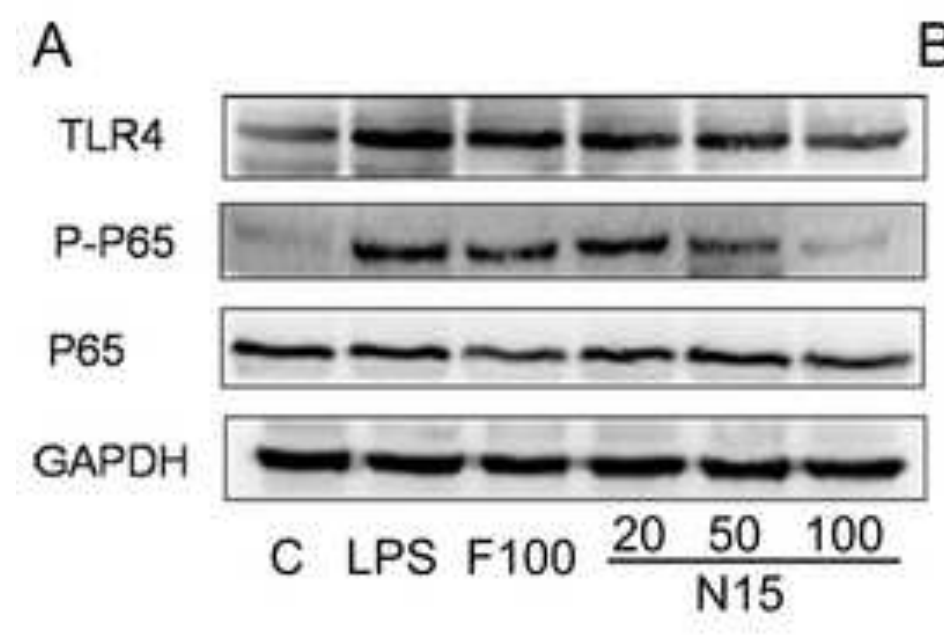

B

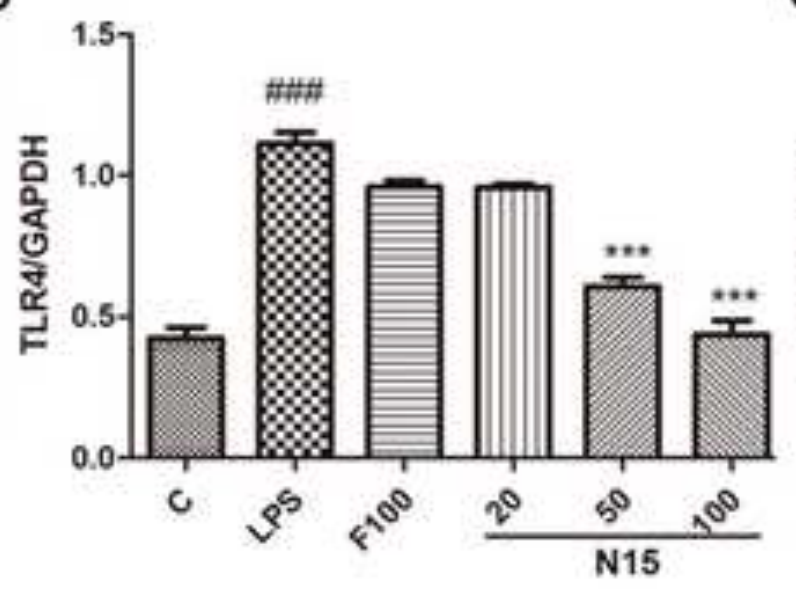

D
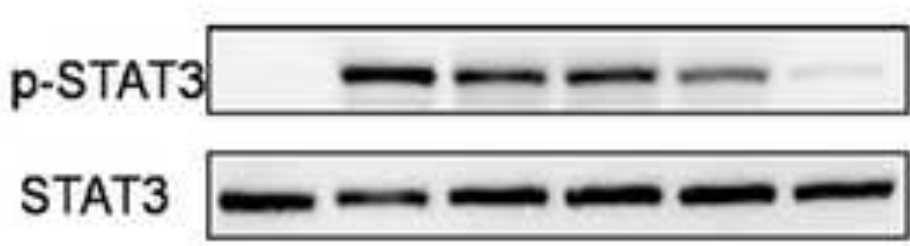
GAPDH

C LPS F100 $\frac{20 \quad 50 \quad 100}{\mathrm{~N} 15}$

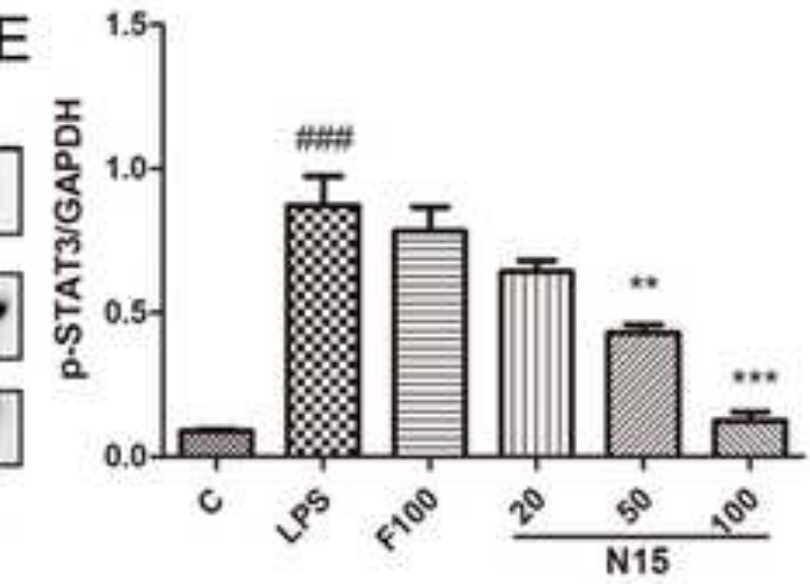

C

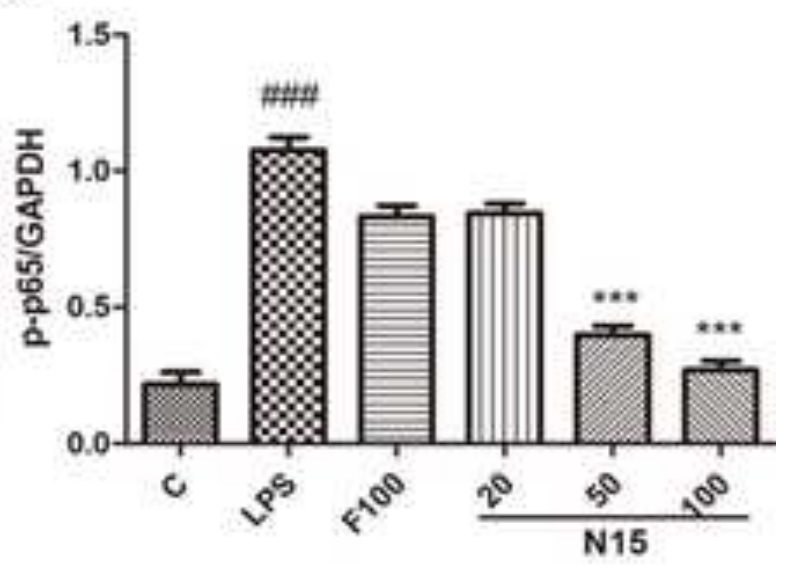




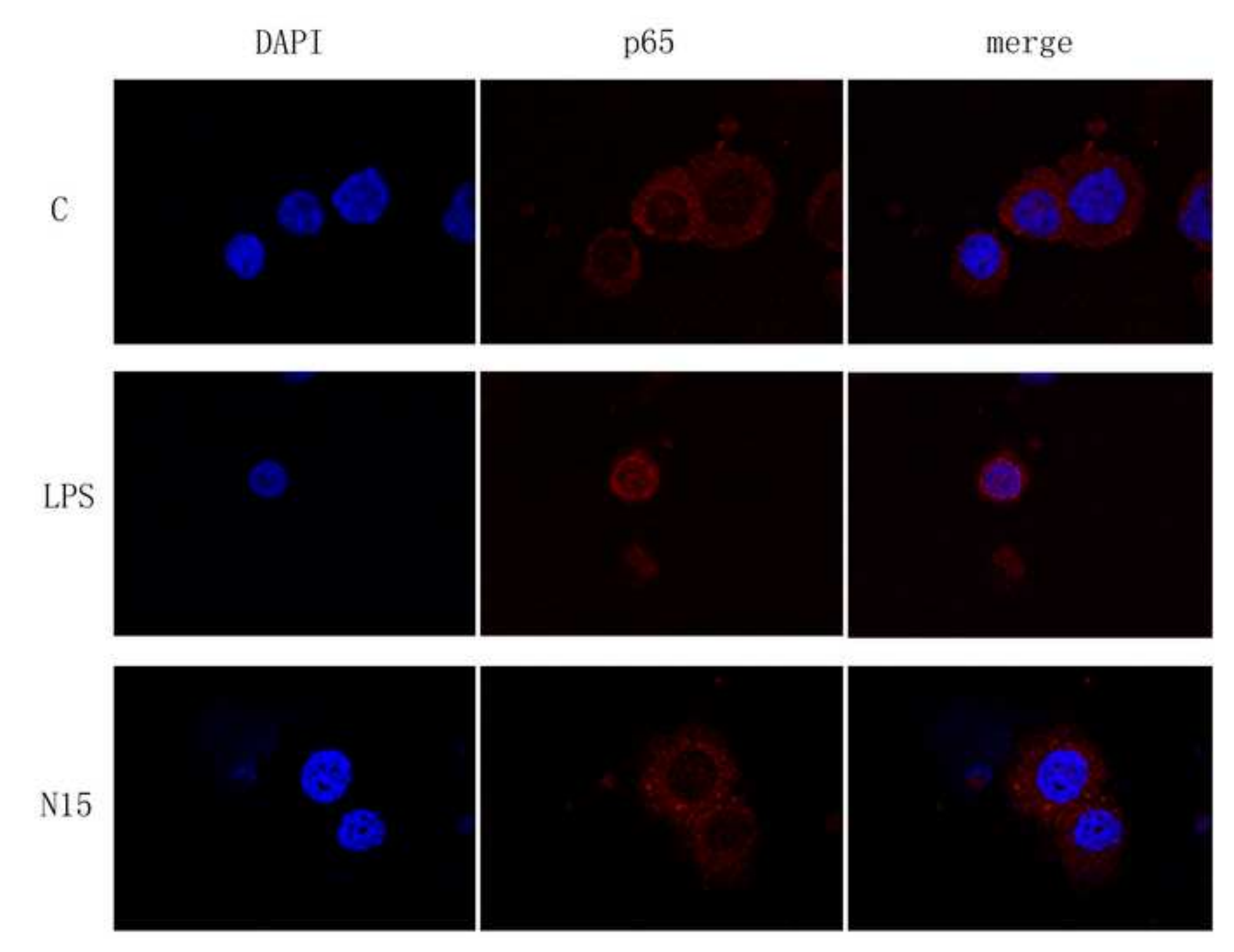


A

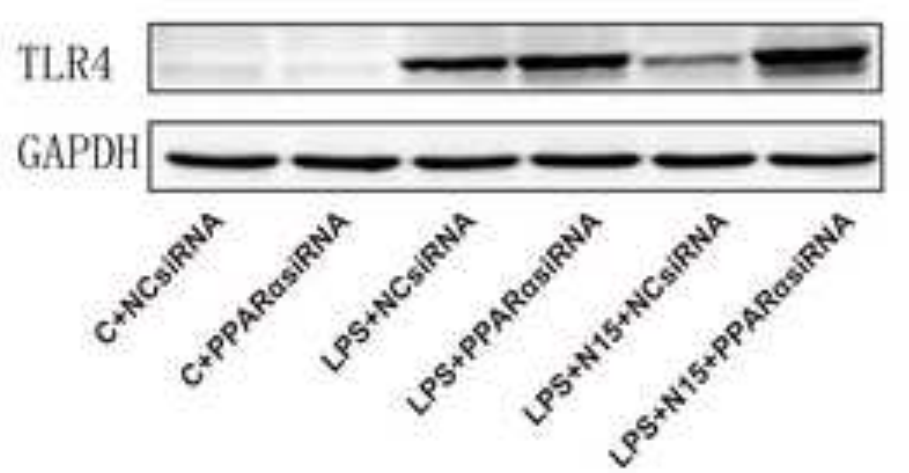

C
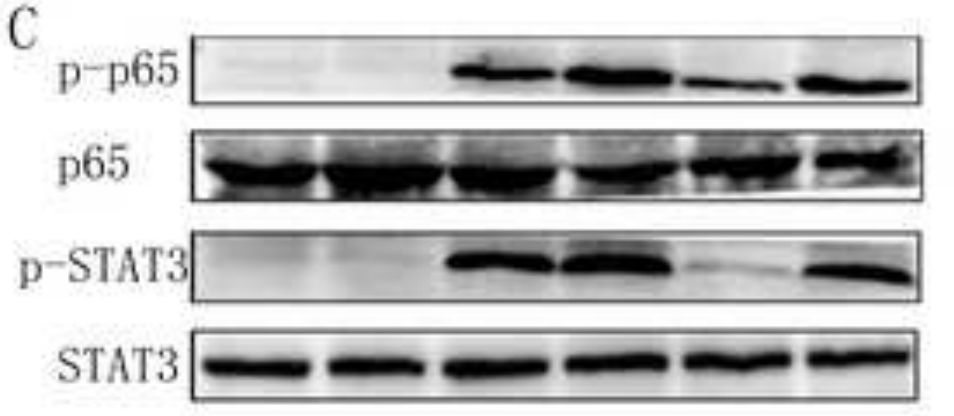

GAPDH

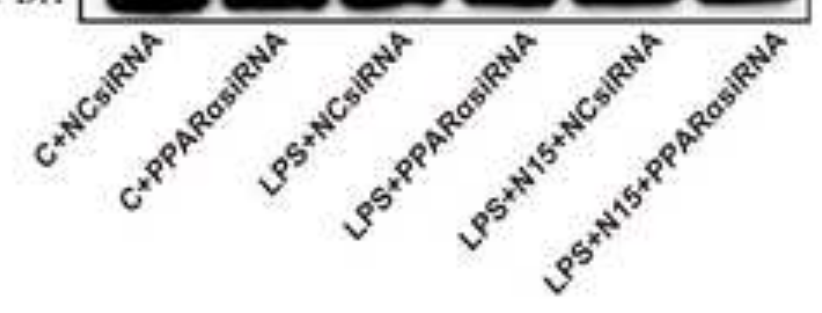

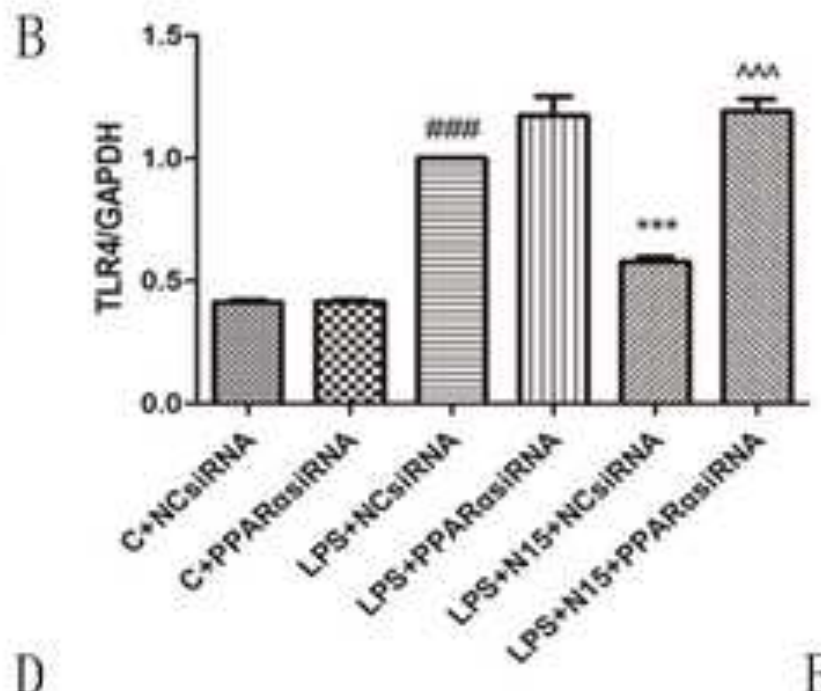

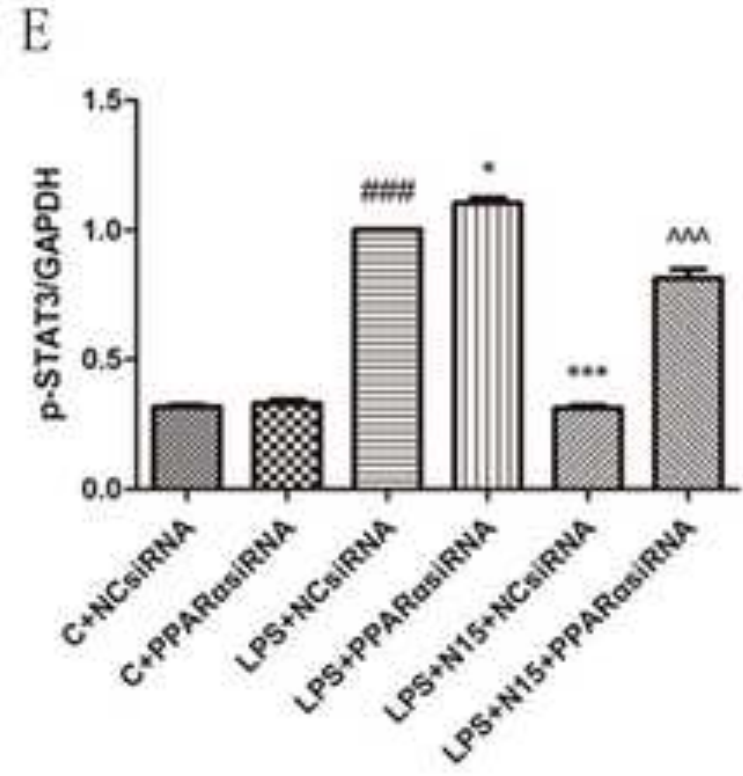

